\title{
Expression profiling of mouse embryonic fibroblasts with a deletion in the helicase domain of the Werner Syndrome gene homologue treated with hydrogen peroxide
}

\author{
Adam Labbé, Ramachander VN Turaga, Éric R Paquet, Chantal Garand, Michel Lebel
}

\begin{abstract}
Background: Werner Syndrome (WS) is a rare disorder characterized by the premature onset of a number of agerelated diseases. The gene responsible for WS encodes a DNA helicase/exonuclease protein believed to affect different aspects of transcription, replication, and/or DNA repair. In addition to genomic instability, human WS cells exhibit oxidative stress. In this report, we have examined the impact of exogenous hydrogen peroxide on the expression profile of mouse embryonic fibroblasts lacking part of the helicase domain of the WRN homologue (here referred to as $W r n^{\Delta h e l / \Delta h e l}$ ).

Results: $W r^{\Delta h e l / \Delta h e l}$ mutant mouse embryonic fibroblasts exhibit increased oxidative stress. This was reflected by increased intracellular reactive oxygen species (ROS), increased oxidative damage in genomic DNA, changes in ATP/ADP ratios, and a disruption of the inner mitochondrial transmembrane potential when compared to wild type mouse embryonic fibroblasts. Expression profile analyses of hydrogen peroxide-treated wild type cells have indicated significant decreases in the expression of genes involved in mitosis, glycolysis, fatty acid metabolism, nucleic acid metabolism, and cell cycle control, as well as protein modification and stability. Such decreases in these biological processes were not observed in hydrogen peroxide-treated $W r n^{\Delta h e l / \Delta h e l}$ cells. Importantly, untreated $W r n^{\Delta h e l / \Delta h e l}$ cells already exhibited down regulation of several biological processes decreased in wild type cells that had been treated with hydrogen peroxide.

Conclusion: Expression profiling of Wrn ${ }^{\Delta h e l / \Delta h e l}$ mutant cells revealed a very different response to exogenous addition of hydrogen peroxide in culture compared to wild type cells. This is due in part to the fact that $W \mathrm{rn}^{\Delta h e l l}$ $\Delta$ hel mutant cells already exhibited a modest chronic intracellular oxidative stress.
\end{abstract}

\section{Background}

It is well established that increased levels of reactive oxygen species (ROS) are involved in a number of diseases including diabetes, complications from obesity, atherosclerosis, and cancer [1-3]. A major source of endogenous ROS comes from the mitochondria during the process of oxidative phosphorylation to produce energy in the form of ATP. In addition, ROS are produced by intracellular membrane oxidases following stimulation either with platelet-derived growth factors, TNF- $\alpha$, or

\footnotetext{
* Correspondence: michel.lebel@crhdq.ulaval.ca

Centre de Recherche en Cancérologie de l'Université Laval, Hôpital Hôtel-
} Dieu de Québec, Québec, Canada

(c) 2010 Labbé et al; licensee BioMed Central Ltd. This is an Open Access article distributed under the terms of the Creative Commons Attribution License (http://creativecommons.org/licenses/by/2.0), which permits unrestricted use, distribution, and reproduction in any medium, provided the original work is properly cited. insulin [1-3]. Inflammation is also a major source of ROS at sites of tissue fibrosis [1-3]. It is thus important for the cell to rapidly neutralize ROS before they can damage cellular macromolecules including DNA. A major DNA lesion generated by excessive ROS is 8-oxo-2'-deoxyguanosine, which leads to a single or double strand break when left unrepaired [4]. Persistent breaks can in turn lead to genomic instability. It is widely believed that the accumulation of mutations is a main cause of several aging processes [5]. In addition, oxidative stress is known to shorten telomeres [6] a process likely leading to replicative senescence and aging as well [7]. Thus, an abnormal response to constant increased levels of endogenous intracellular ROS would likely affect aging $[8,9]$. 
Some specific inherited monogenic diseases appear to modulate multiple aspects of aging. They are referred as segmental progeroid syndromes. A common feature of all progeroid syndromes is genomic instability. One such syndrome is Werner syndrome (WS) also known as "Progeria of the Adult" [10]. WS is an autosomal recessive disorder characterized by genomic instability and the premature onset of a number of age related diseases $[11,12]$. The gene responsible for WS (WRN) was identified by positional cloning and encodes a protein containing a RecQ-type helicase consensus domain [13]. It was subsequently found that, in addition to a 3'-5' helicase activity, the WRN protein also possesses a 3'-5' exonuclease activity $[14,15]$. It has been recently proposed that WRN protein may be required for the repair of oxidative DNA damage [16] including oxidative DNA damage at telomeres [17].

Remarkably, increased oxidative stress was described for WS patients [18]. Furthermore, human WS fibroblasts exhibit increased intracellular oxidized protein content [19]. Increased oxidative stress was also observed in embryonic cells derived from mice lacking part of the helicase domain [20]. In this study, we sought to determine the impact of additional oxidative stress in mouse embryonic fibroblasts lacking part of the helicase domain of the WRN gene ortholog. Expression profiling analyses of $\mathrm{Wrn}{ }^{\Delta h e l / \Delta h e l}$ mutant cells revealed a very different response to addition of hydrogen peroxide in culture compared to wild type cells as they already exhibit a modest but significant chronic increase in intracellular ROS levels.

\section{Results}

Oxidative stress in $W r n^{\Delta h e l / \Delta h e l}$ mouse embryonic fibroblasts

Previous data have indicated that $\mathrm{Wrn}^{\Delta h e l / \Delta h e l}$ mouse embryonic fibroblasts acquire a slower growth rate than wild type fibroblasts with the number of passages in culture [21]. In addition, $\mathrm{Wr} n^{\Delta h e l / \Delta h e l}$ mutant cells exhibit increased chromosomal rearrangements with the number of passages in culture [22]. As oxidative DNA damage can lead to chromosomal rearrangements, levels of intracellular ROS and the extent of oxidative DNA damage were measured in wild type and $\mathrm{Wrn}^{\Delta h e l / \Delta h e l}$ embryonic fibroblasts. Intracellular ROS levels were examined directly in mouse embryonic fibroblasts with the dye 2'-7' dichlorofluorescein diacetate. This dye is highly fluorescent upon oxidation. Cells in the presence of the dye were lysed and the extent of fluorescence released from cells was measured with a fluorescence spectrophotometer as described previously [23]. As shown in Figure 1A, ROS levels were $10 \%$ higher in $W_{r n} n^{\Delta h e l / \Delta h e l}$ cells $(t$-test; $P<0.05)$ compared to wild type cells. Concomitantly, there were on average 51 abasic sites per pg of genomic DNA in wild type cells and 64 abasic sites per pg of genomic DNA in $\mathrm{Wrn}^{\Delta h e l /}$ $\Delta$ hel cells, a $20 \%$ increase in the mutant cells $(t$-test; $P<$ 0.05) (Figure 1B). These results indicate that $\mathrm{Wrn}^{\Delta \text { hel }}$ $\Delta$ hel cells exhibit a modest but significant increase in oxidative stress.

Since a cellular redox change may decrease energy production in the form of ATP from mitochondria, we next examined intracellular ATP levels and mitochondrial membrane potential. As shown in Figure $1 \mathrm{C}$, the ATP level in $\mathrm{Wrn}^{\Delta h e l / \Delta h e l}$ mutant cells was 30\% lower than wild type cells. Consequently, the ADP/ATP ratio

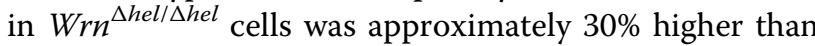
wild type cells (Figure 1D). A lower ATP production might be a consequence of disruption of the inner mitochondrial transmembrane potential in mutant cells. The mitochondrial membrane potential was thus examined in our mouse embryonic fibroblasts with the fluorescent dye tetramethylrhodamine ethyl ester (TMRE) As indicated in Figure 1E, fluorescence intensity was 30\% lower

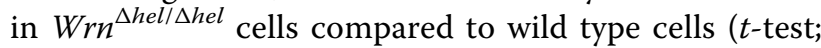
$P<0.03)$. Taken together, these results indicate a disturbance of mitochondrial activities in $\mathrm{Wrn}^{\Delta h e l / \Delta h e l}$ mutant cells.

Glutathione (GSH) is the principal intracellular lowmolecular-weight thiol and it plays a critical role in the defense against oxidative stress in mammalian cells. We wanted to know whether the abundance of this molecule is affected in mutant cells. Levels of GSH were thus quantified in our mouse wild type and $\mathrm{Wrn}^{\Delta h e l / \Delta h e l}$ mutant embryonic fibroblasts. Remarkably, levels of

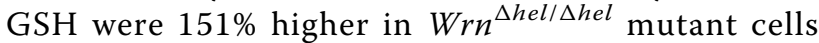
compared to wild type cells $(t$-test; $P<0.001)$ (Figure 2). These results suggest that $W r n^{\Delta h e l / \Delta h e l}$ mutant cells display an adaptive response to oxidative stress. This response was further examined by treating cells with exogenous $\mathrm{H}_{2} \mathrm{O}_{2}$. Cells were treated one hour with 0.5 $\mathrm{mM} \mathrm{H}_{2} \mathrm{O}_{2}$ and $\mathrm{GSH}$ levels were measured 24 hours later. As indicated in Figure 2, $\mathrm{H}_{2} \mathrm{O}_{2}$ induced a $178 \%$ increase in GSH levels in wild type cells $(t$-test; $P<$ $0.001)$. There was no significant increase in GSH levels in $\mathrm{Wrn}^{\Delta h e l / \Delta h e l}$ mutant cells. As indicated above GSH levels were already high in untreated $\mathrm{Wrn}^{\Delta h e l / \Delta h e l}$ cells. These results indicate that $\mathrm{Wrn}^{\Delta h e l / \Delta h e l}$ mutant cells continuously exhibited an increased anti-oxidant response.

\section{Expression profiling of mouse embryonic fibroblasts treated with $\mathrm{H}_{2} \mathrm{O}_{2}$}

Little is known about the global response to $\mathrm{H}_{2} \mathrm{O}_{2}$ in wild type and $\mathrm{Wrn}^{\Delta h e l / \Delta h e l}$ mouse embryonic fibroblasts. To compile a list of $\mathrm{H}_{2} \mathrm{O}_{2}$-responsive genes, we compared wild type cells before and after oxidative cellular stress. Cells were treated with $\mathrm{H}_{2} \mathrm{O}_{2}$ for one hour, fed with fresh 


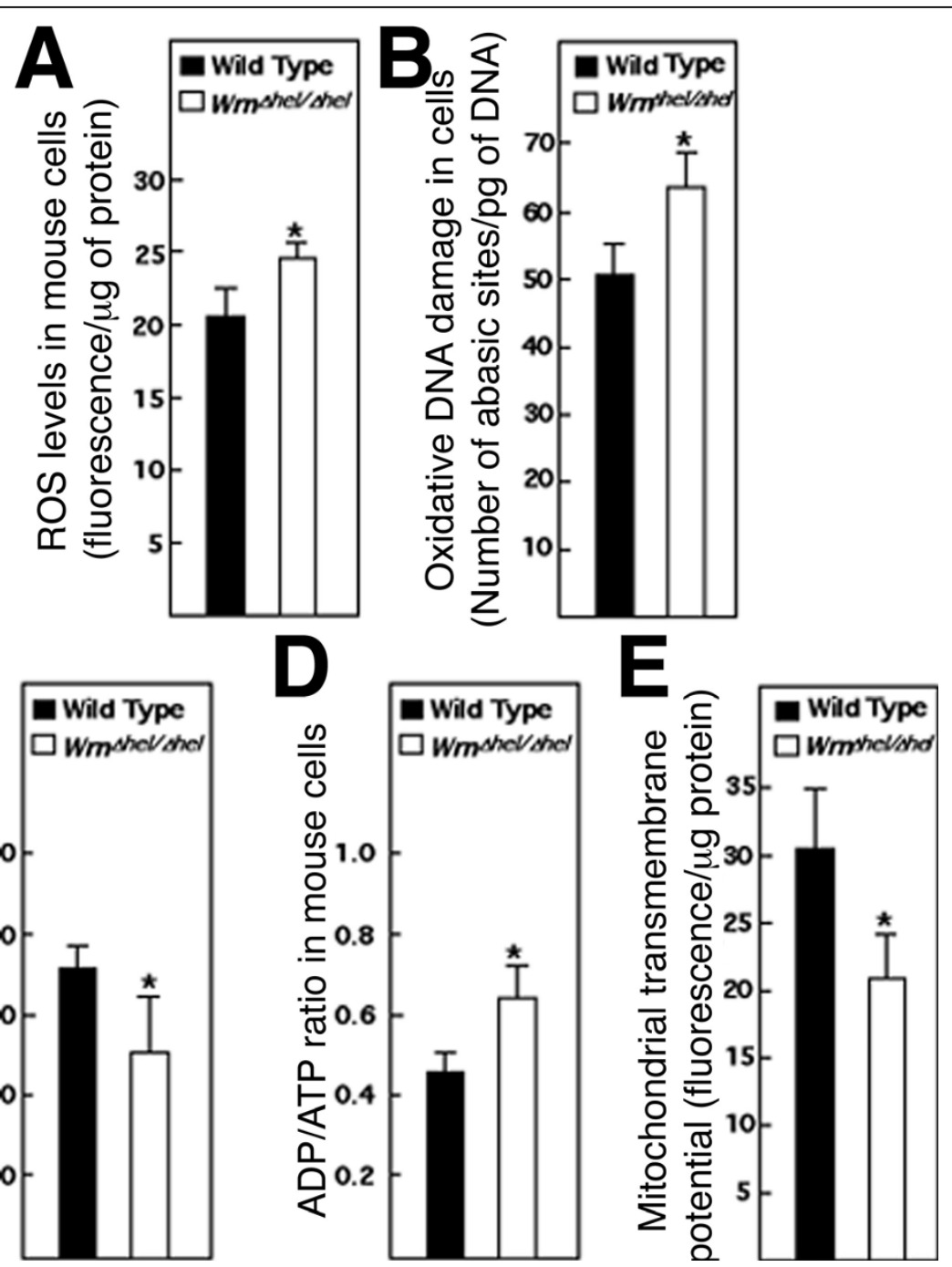

Figure 1 Increased oxidative stress in mutant mouse embryonic fibrobasts. (A) ROS levels in wild type and $W r n^{\Delta h e l / \Delta h e l}$ cells determined by measuring the intensity of fluorescence by $2^{\prime}, 7^{\prime}$-dichlrofluorescein per $\mu \mathrm{g}$ of protein in cells. Asterisks denote statistical significance compared to wild type cells ( ${ }^{*}$-test: $P<0.05$ ). (B) Oxidative DNA lesions created by ROS in wild type and $W r n^{\Delta h e l / \Delta h e l}$ cell cultures. The number of abasic sites per pg of genomic DNA was detected as described in Materials and Methods. The asterisk denotes statistical significance compared to wild type cells ( ${ }^{*} t$-test: $\left.P<0.05\right)$. (C) ATP levels in wild type and $W r n^{\Delta h e l / \Delta h e l}$ cells. Asterisks denote statistical significance compared to wild type cells $\left({ }^{*} t\right.$ test: $P<0.05)$. (D) ADP/ATP ratios in wild type and $W r n^{\Delta h e l / \Delta h e l}$ cells. Asterisks denote statistical significance compared to wild type cells $\left({ }^{*} t\right.$-test: $P$ $<0.05)$. (E) Inner mitochondrial transmembrane potential in wild type and $W r n^{\Delta h e l / \Delta h e l}$ cells. Mitochondrial membrane potential was measured with the potentiometric dye TMRE. Asterisks denote statistical significance compared to wild type cells $\left({ }^{*} t\right.$-test: $P<0.03$ ). All experiments in this figure were performed in quadruplicate.

media, and cytoplasmic RNA was harvested 24 hours later. Hybridization was performed on Whole Mouse Genome Agilent 60-mer Oligo Microarray chips (containing approximately 44,000 probes) by mixing wild type $\mathrm{Cy}-3-$ labeled cRNA (baseline expression levels) with $\mathrm{H}_{2} \mathrm{O}_{2}$-treated wild type Cy-5-labeled cRNA. Hybridization experiments were performed twice with different wild type biological replicates. The same strategy was adopted for $W_{r n}{ }^{\Delta h e l / \Delta h e l}$ mutant cells. Hybridization was performed by mixing untreated $\mathrm{Wrn}^{\Delta h e l / \Delta h e l}$ mutant Cy-3-labeled cRNA with $\mathrm{H}_{2} \mathrm{O}_{2}$-treated $W r n^{\Delta h e l / \Delta h e l}$ Cy-5-labeled cRNA.
Lists of genes differentially expressed were generated by requiring that the absolute value of the fold change be higher than two, that the $\log 2$ of the expression level (or signal) for each gene be higher than six, and the adjusted $P$-value, using the Benjamini-Hochberg method, be lower than 0.005 . Six hundred and seventy eight genes exhibited a two-fold alteration in mRNA expression level in $\mathrm{H}_{2} \mathrm{O}_{2}$-treated wild type mouse embryonic fibroblasts compared to untreated wild type cells (548 down-regulated and 130 up-regulated, respectively) (additional file 1). Four hundred and twenty one 


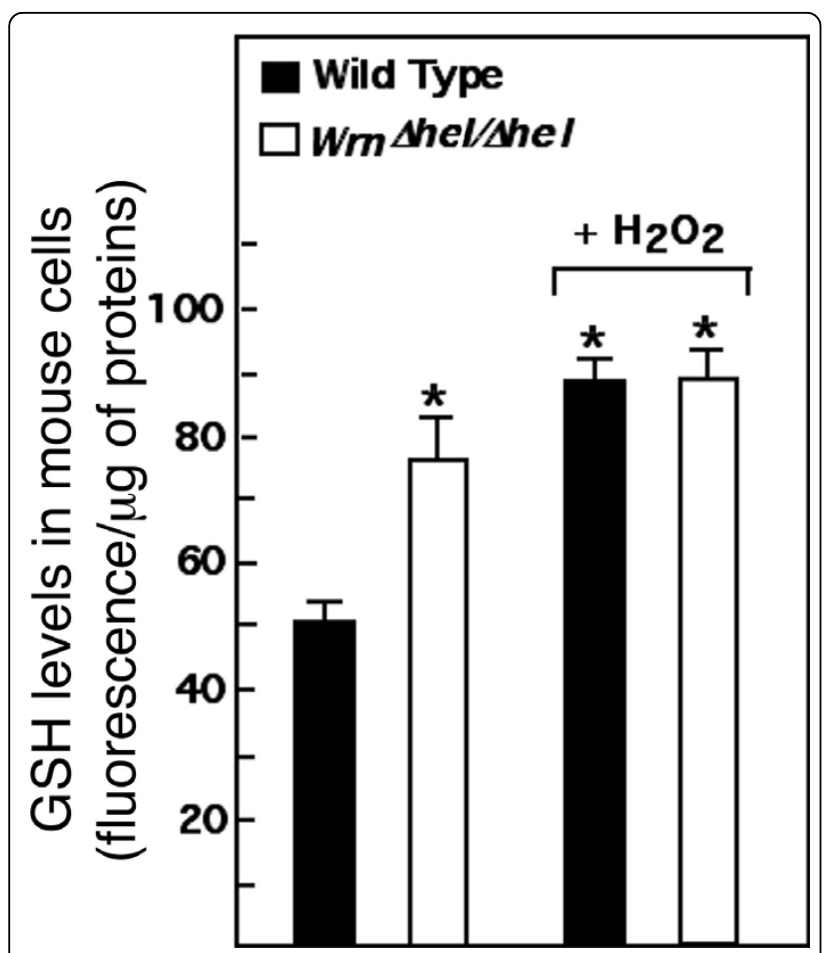

Figure 2 Reduced GSH levels in $\mathrm{H}_{2} \mathrm{O}_{2}$-treated and untreated wild type and $W r n^{\Delta h e l / \Delta h e l}$ mouse embryonic fibroblasts determined by the intensity of fluorescence per $\mu \mathrm{g}$ of protein Fluorescence of reduced GSH was detected with the ApoGSH glutathione detection kit (Bio Vision Mountain View, CA). Oxidative stress was induced by treating cells with $0.5 \mathrm{mM} \mathrm{H}_{2} \mathrm{O}_{2}$ one hour and fresh medium was then added for an additional 24 hours to allow the cells to recover before measurements. ${ }^{*} t$-test: $P<0.001$ compared to untreated wild type mouse embryonic fibroblasts).

genes exhibited a two-fold alteration in expression in $\mathrm{H}_{2} \mathrm{O}_{2}$-treated $\mathrm{Wrn}^{\Delta \text { hel/shel }}$ mouse embryonic fibroblasts compared to untreated $\mathrm{Wrn}^{\Delta h e l / \Delta h e l}$ cells (368 downregulated and 53 up-regulated, respectively) (additional file 2). One hundred and seventy five genes were altered

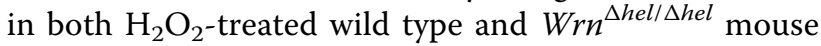
embryonic fibroblasts (Figure $3 \mathrm{~A}$ and additional file 3 ).

Real time RT-PCR was performed on seven randomly picked genes from the untreated versus $\mathrm{H}_{2} \mathrm{O}_{2}$-treated wild type mouse embryonic fibroblasts data (additional file 1) to confirm our microarray analyses (Table 1). A list of the primers for the genes analyzed is shown in the additional file 4. Overall, the fold changes observed by real time RT-PCR were in good agreement with the predicted fold changes from the microarray data highlighted by a significant Spearman's correlation (rho = 0.9286; $P=0.0067)$.

The PANTHER classification system was used to classify differentially expressed genes by their functions in specific biological processes. Categorization of the genes in our lists revealed 23 and 5 significantly down regulated biological processes (with a Benjamini value of less than

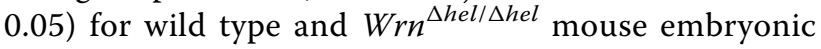
fibroblasts treated with $\mathrm{H}_{2} \mathrm{O}_{2}$, respectively (Figure 3). Four processes were commonly down regulated in wild type and $\mathrm{Wrn}^{\Delta h e l / \Delta h e l}$ mouse embryonic fibroblasts treated with $\mathrm{H}_{2} \mathrm{O}_{2}$ and they include genes involved in cation transport, chromatin remodeling, cell motility, and developmental processes (or cellular differentiation) (Figure $3 \mathrm{~B}$ and $3 \mathrm{C}$ ). The only additional biological process that was down regulated in $\mathrm{Wrn}^{\Delta h e l / \Delta h e l}$ mouse embryonic fibroblasts corresponded to the cellular defense response requiring antigen presentation during major histo-compatibility complex II molecule (MHCII)mediated immunity. Wild type mouse embryonic fibroblasts treated with $\mathrm{H}_{2} \mathrm{O}_{2}$ also exhibited decreases in biological pathways affecting protein and vesicle transportation, cell surface mediated signal transduction, cell cycle and proliferation, nucleic acid metabolism, several types of protein modification and folding, proteolysis, glycolysis, and mitosis (Figure 3C). Finally, based on PANTHER analysis no biological pathway was significantly up regulated in either $\mathrm{H}_{2} \mathrm{O}_{2}$-treated wild

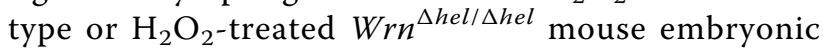
fibroblasts.

\section{Several biological processes are already decreased in untreated $W r n^{\Delta h e l / \Delta h e l}$ mouse embryonic fibroblasts}

We also performed PANTHER analysis on the list of genes differentially expressed between untreated wild type and untreated $\mathrm{Wrn}^{\Delta h e l / \Delta h e l}$ mouse embryonic fibroblasts. Differentially expressed genes between $\mathrm{Wrn}^{\Delta \text { hell }}$ $\Delta$ hel and wild type mouse embryonic fibroblasts were selected by requiring that the $\log 2$ of the expression level for each gene be higher than six and the adjusted $P$-value, using the Benjamini-Hochberg method, be lower than 0.005 (additional file 5). Figure 4A indicates that biological processes such as protein folding, protein metabolism and modification, proteolysis, G-proteinmediated signaling, cation transport, and developmental processes were significantly down regulated in $\mathrm{Wrn}^{\Delta h e l /}$ $\Delta$ hel mouse embryonic fibroblasts compared to wild type cells (with a Benjamini value < 0.05). Purine metabolisms, as well as amino acid metabolism and biosynthesis processes, were up regulated in $\mathrm{Wrn}^{\Delta h e l / \Delta h e l}$ mouse embryonic fibroblasts compared to wild type cells. These results indicate that all the biological processes

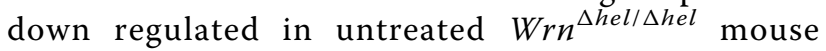
embryonic fibroblasts (compared to untreated wild type cells) were also down regulated in $\mathrm{H}_{2} \mathrm{O}_{2}$-treated wild type mouse embryonic fibroblasts (Figure 4B).

\section{Discussion}

We have previously observed increased oxidative stress in mouse embryonic fibroblasts established from 


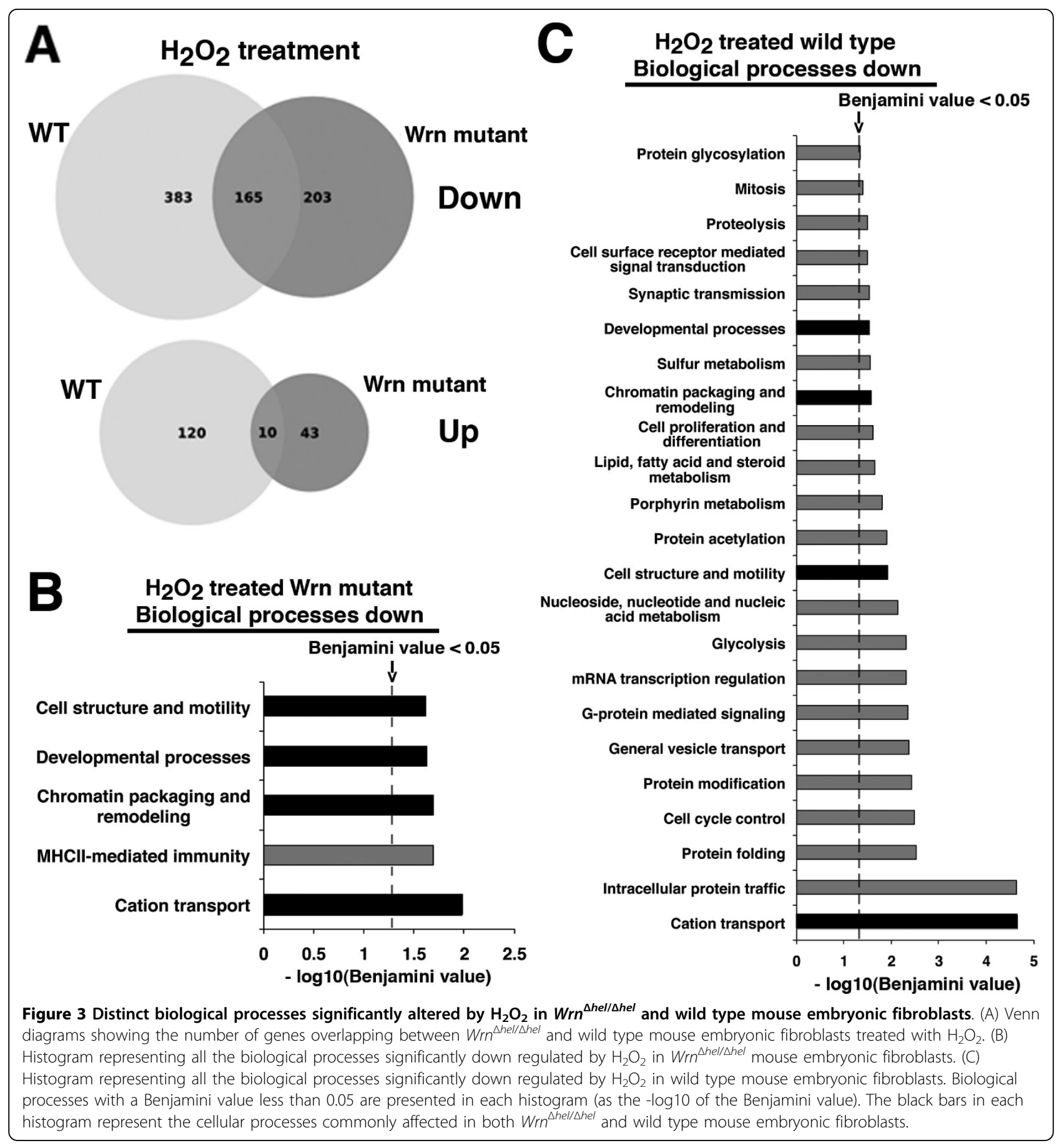

$W_{r n}^{\Delta h e l / \Delta h e l}$ mice compared to wild type cells [20]. In this study, we further explored this phenotype by examining the expression profile of such cells. $\mathrm{Wrn}^{\Delta h e l / \Delta h e l}$ mutant cell lines exhibited a 10\% increase in ROS levels compared to wild type cells (baseline level). Importantly, the high levels of GSH in $\mathrm{Wrn}^{\Delta h e l / \Delta h e l}$ mutant cells confirmed indirectly the increased oxidative stress in such cells. In fact, GSH levels in $\mathrm{Wr} n^{\Delta h e l / \Delta h e l}$ mutant cells were almost as high as wild type cells that had been treated with exogenous $\mathrm{H}_{2} \mathrm{O}_{2}$ (Figure 2). Further analysis of cells with the potentiometric dye TMRE has indicated a lower mitochondrial transmembrane potential in $W r n^{\Delta h e l / \Delta h e l}$ mutant cells. At the same time, we detected a lower amount of ATP in the mutant cells compared to wild type cells. Production of lower quantities of ATP by mitochondria may in part be responsible for the slow growth phenotype associated with $\mathrm{Wrn}^{\Delta h e l / \Delta h e l}$ cells [20]. The increase in ROS concomitant with the high 
Table 1 Correlation of the real time RT-PCR-derived values with the microarray data from wild type mouse embryonic fibroblasts treated with peroxide.

\begin{tabular}{lcc}
\hline Gene & $\begin{array}{c}\text { Fold change in } \\
\text { microarray }\end{array}$ & $\begin{array}{c}\text { Fold change } \\
\text { from RT-PCR }\end{array}$ \\
\hline Ero1L (endoplasmic reticulum & +2.84 & +2.76 \\
oxidoreductase 1-like) & -2.19 & -1.45 \\
Fn1 (fibronectin-1) & +2.25 & +1.71 \\
Mt1 (metallomethionin-1) & & \\
Mt2 (metallomethionin-2) & +2.68 & +1.65 \\
Nqo1 (NAD(P)H & & +1.63 \\
dehydroxygenase, quinone 1) & +2.06 & +7.97 \\
Txnrd1 (thioredoxin reductase 1) & +3.72 & \\
Uchl1 (ubiquitin carboxy- & & \\
terminal hydrolase L1) & & \\
\hline
\end{tabular}

Spearman's correlation between microarray and RT-PCR data: rho $=0.9286$ $p$-value $=0.0067$

levels of GSH and the lower energy production (ATP) by mitochondria in $\mathrm{Wrn}^{\Delta h e l / \Delta h e l}$ mouse embryonic fibroblasts are consistent with the phenotypes observed in the liver tissue of $\mathrm{Wrn}^{\Delta h e l / \Delta h e l}$ mice [24]. Wrn ${ }^{\Delta h e l / \Delta h e l}$ mice exhibit increased GSH levels in liver tissue with increased ROS, DNA damage and decrease ATP levels with age. These results suggest that the observed anomalies in the $\mathrm{Wrn}^{\Delta h e l / \Delta h e l}$ mice are observable at the cellular level with mouse embryonic fibroblasts in culture. Such results suggest that cells in a given tissue already exhibit a modest but chronic intracellular prooxidative status. In accord with this, a pro-oxidative status has been described for WS patients [18].

Our prediction was that an exogenous addition of ROS to $\mathrm{Wrn}^{\Delta h e l / \Delta h e l}$ mutant cells would exacerbate the intracellular metabolic anomalies and damage as the anti-oxidative system of such cells is already saturated (at least for the GSH system) while coping with a chronic higher intracellular level of ROS. The results obtained with mouse embryonic fibroblasts treated with an exogenous source of $\mathrm{H}_{2} \mathrm{O}_{2}$ are highly relevant since additional ROS at the tissue level may follow each meal due to increased sugar and lipid levels in the blood stream after ingestion. Increased sugar and lipids will potentially impact on the cellular redox status of cells in several tissues $[25,26]$.

The impact of $\mathrm{H}_{2} \mathrm{O}_{2}$ on the expression profile of Wrn mutant cells has not been previously analyzed. Microarray analyses indicated that $\mathrm{Wrn}^{\Delta h e l / \Delta h e l}$ mouse embryonic fibroblasts respond very differently from wild type cells to exogenous $\mathrm{H}_{2} \mathrm{O}_{2}$. These results are consistent with the observation that human WS cells respond differently to $\mathrm{H}_{2} \mathrm{O}_{2}$ when compared to cells with a functional WRN gene product $[27,28]$. Again, this difference maybe due to the fact that cells with a mutation in the Wrn gene are already exhibiting chronic increased oxidative stress in culture [20,29]. Significant decreases in the expression of

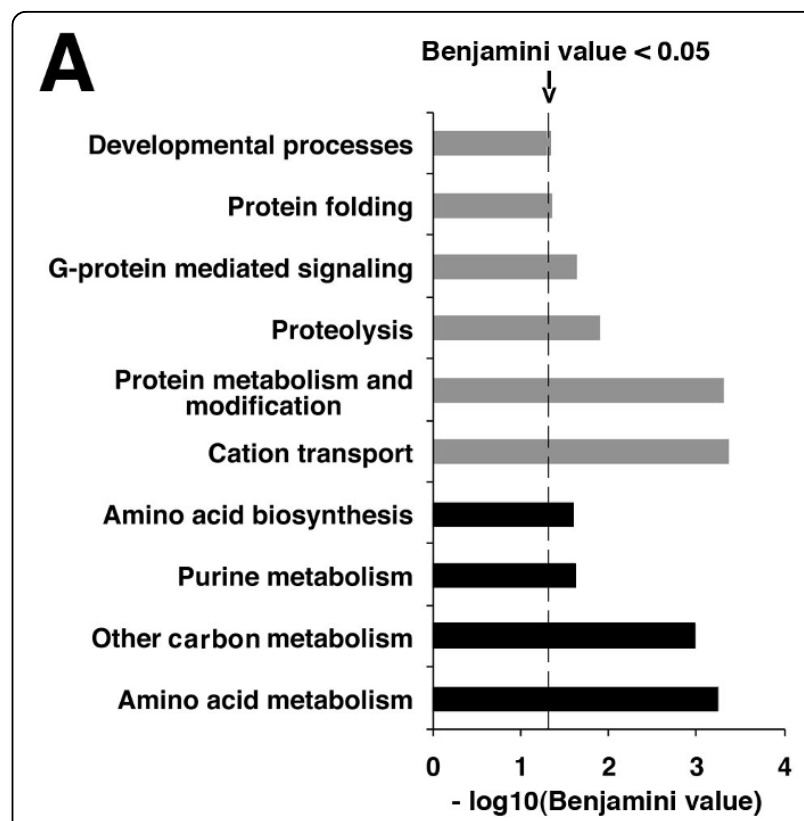

B

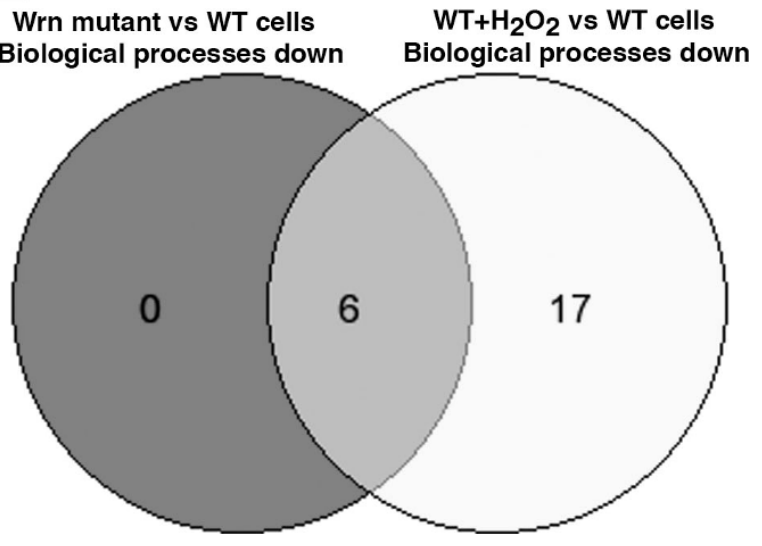

Figure 4 Histogram indicating the major biological processes in untreated $W_{r n}{ }^{\Delta h e l / \Delta h e l}$ mouse embryonic fibroblasts significantly changed compared to untreated wild type cells. (A) The biological processes with a Benjamini value less than 0.05 are presented for untreated $W r n^{\Delta h e l / \Delta h e l}$ mouse embryonic fibroblasts versus untreated wild type cells (baseline level) as the -log10 of the Benjamini value. The black and gray bars represent the up and down regulated cellular processes, respectively. (B) Venn diagrams showing the number of down regulated biological processes overlapping between untreated $\mathrm{Wrn}^{\Delta h e l / \Delta h e l}$ and $\mathrm{H}_{2} \mathrm{O}_{2}$-treated wild type mouse embryonic fibroblasts.

genes involved in mitosis, glycolysis and fatty acid metabolism (energy production), nucleic acid metabolism, cell cycle control, as well as protein modification and stability were observed in $\mathrm{H}_{2} \mathrm{O}_{2}$-treated wild type embryonic fibroblasts. Such dramatic decreases in these biological processes were not observed in $\mathrm{H}_{2} \mathrm{O}_{2}$ treated $\mathrm{Wrn}^{\Delta \text { hel/ } / \Delta \mathrm{hel}}$ cells. Interestingly, untreated $\mathrm{Wrn}^{\Delta h e l / \Delta h e l}$ cells already exhibited changes in several of these biological processes 
before the addition of $\mathrm{H}_{2} \mathrm{O}_{2}$ suggesting again a chronic oxidative stress in these mutant cells. A likely deleterious consequence of responding differently to additional ROS is a greater increase in the presence of persistent DNA breaks and the rapid accumulation of chromosome rearrangements compared to wild type mouse embryonic fibroblasts [22].

The International Registry of Werner Syndrome http://www.wernersyndrome.org has provided molecular diagnosis of WS for over a decade. Fifty distinct mutations inactivating the WRN protein have been described in WS patients to date [30]. These mutations include missense and nonsense substitutions, frame shifts and premature translation termination mutations, deletions and insertions. All these mutations are believed to disrupt the normal function of WRN protein or to cause a truncation of the protein that cannot localize to the nucleus, the normal site of WRN protein action. Some mutations also cause abnormally rapid degradation of the WRN protein. Our mouse model has an in-frame deletion in the helicase domain of the Wrn protein, which is as stable as the normal protein [31]. However, the mutant protein does not stably interact with the DNA replication complex [32] suggesting that this mutation in mouse severely affects the overall function of the mutant Wrn protein. Although thorough biochemical analyses of this mutant protein are required, the $\mathrm{Wrn}$ helicase mutant mice provide a compelling model as they exhibit most metabolic abnormalities observed in human WS patients [23,24].

\section{Conclusion}

To conclude, untreated $\mathrm{Wr} n^{\Delta h e l / \Delta h e l}$ mutant cells exhibit increased ROS generation due to alterations in mitochondrial activities. The exact reason for such mitochondrial alterations is unknown but mitochondrial dysfunction is well known to lead to physiological decline with age [9]. We recently observed that a transient knock down of WRN protein in human fibroblasts is sufficient to change the expression of genes involved in lipidogenesis [33]. Such changes are known to affect the redox status in cells, which in turn affects mitochondrial function [34]. Interestingly, we have also observed that $\mathrm{Wrn}^{\Delta h e l / \Delta h e l}$ mutant mice exhibit increased rate of point mutations in the mitochondrial DNA of liver and heart tissues [24], which can potentially lead to further mitochondrial dysfunction with age. Finally, a transient knock down of WRN in human fibroblasts will increase the activity of several protein kinase $C$ enzymes including $\mathrm{PKC} \delta$ [29]. PKC $\delta$ is known to modulate ROS production from mitochondria [35]. Hence, there is the interesting possibility that depletion of WRN activates $\mathrm{PKC} \delta$, which in turn modulates ROS production from mitochondria. Indeed, a decreased production of ROS in
WRN-depleted fibroblasts can be observed by knocking down PKC $\delta$ protein levels in such cells. Future appropriate experiments will determine which pathways, transcription regulation of specific metabolic genes or activation of specific kinases, are responsible for the redox imbalance seen in human WRN mutant or mouse $W r n^{\Delta h e l / \Delta h e l}$ cells.

\section{Methods}

\section{Primary mouse embryonic fibroblasts and RNA}

Mice lacking part of the helicase domain of the $\mathrm{Wrn}$ gene were generated by homologous recombination in mouse embryonic stem cells [31]. In the process, 121 amino acid residues of the Wrn protein were deleted (amino acids 710 to 831 ). The genetic background of these mice was both 129/Sv and Black Swiss (129/Sv/Black Swiss genetic background). Care of mice was in accordance with the guidelines of the Committee for the protection of animals at the Universite Laval. Generation and maintenance of the embryonic cells has been described previously [21]. Briefly, healthy 15.5-day old embryos were minced in 6-well plates and maintained in low glucose DMEM supplemented with $10 \%$ heat-inactivated calf serum at $37^{\circ} \mathrm{C}$ in an atmosphere of $5 \% \mathrm{CO}_{2}$. Adherent cells established from embryonic tissues were passaged as soon as they reached confluence. Cytoplasmic RNA was extracted according to standard protocols [36]. After DNAse treatment and phenol:chloroform extraction, precipitated cytoplasmic RNA was dissolved in RNase-free water and purity was verified with an Agilent 2100 bioanalyzer (Agilent, Palo Alto, CA).

\section{Microarray analysis}

Duplicated biological RNA samples (wild type versus $\mathrm{H}_{2} \mathrm{O}_{2}$-treated wild type; $W r n^{\Delta h e l / \Delta h e l}$ versus $\mathrm{H}_{2} \mathrm{O}_{2}$-treated $\mathrm{Wrn}^{\Delta h e l / \Delta h e l}$ cells; wild type versus $\mathrm{Wrn}^{\Delta h e l / \Delta h e l}$ ) were labeled with Cyanin-3 or -5 labeled CTP (PerkinElmer, Boston, MA). Labeled cRNAs were purified using the RNeasy Mini kit (Qiagen, Mississauga, $\mathrm{ON}$ ) and were hybridized onto Whole Mouse Genome Agilent 60-mer Oligo Microarrays (44,000 probes/microarray) using the in situ Hybridization Plus kit (Agilent, Palo Alto, CA) following the manufacturer's instructions. Arrays were scanned using a dual-laser DNA microarray scanner. Data were then extracted from images by the Feature Extraction software 6.1 (Agilent, Palo Alto, CA). Lists of differentially expressed genes were generated using limma in BioConductor http://www.bioconductor.org. The data were background subtracted and normalized using the loess method. Correction for multiple hypothesis testing was performed using the Benjamini-Hochberg method. We have deposited all the raw data in the NCBI public database Gene Expression Omnibus http://www.ncbi.nlm.nih. gov/geo/ [accession series number GSE19007]. 


\section{Bioinformatic analyses}

The PANTHER (Protein ANalysis THrough Evolutionary Relationships) classification system is a unique resource that classifies genes by their functions, using published scientific experimental evidence and evolutionary relationships to predict function even in the absence of direct experimental evidence. Proteins are classified by expert biologists into families and subfamilies of shared function, which are then categorized by molecular function and biological process ontology terms. This program is implemented in the DAVID (Database for Annotation, Visualization, and Integrated Discovery) web site [37]. Enrichments for specific biological functions using PANTHER were considered significant with a Benjamini value smaller than 0.05 . The Benjamini value corresponds to an adjusted $p$-value using the Benjamini-Hochberg method to correct for multiple hypotheses tested during gene enrichment analyses.

\section{Measurements of reactive oxygen species}

Mouse embryonic fibroblasts were incubated with 10 $\mu \mathrm{g} / \mu \mathrm{l}$ of the dye 2'-7' dichlorofluorescein diacetate (Sigma-Aldrich Canada Ltd., Oakville, ON) for one hour at $37^{\circ} \mathrm{C}$. This dye is highly fluorescent upon oxidation. After this incubation time, cells were harvested and lysed in RIPA buffer [50 mM Tris- $\mathrm{HCl}$ (pH 7.5), 150 $\mathrm{mM} \mathrm{NaCl}, 1 \% \mathrm{NP}-40,0.1 \%$ SDS, $0.5 \%$ sodium deoxycholate] for 10 minutes. Cell debris were spun down and $100 \mu \mathrm{l}$ of lysate was transferred to 96-well plates for fluorescence measurements with a Fluoroskan Ascent fluorescence spectrophotometer (Thermo Electron Inc., Milford, MA). The excitation and emission wavelengths used were $485 \mathrm{~nm}$ and $527 \mathrm{~nm}$, respectively. The final result was expressed as units of fluorescence per $\mu \mathrm{g}$ of proteins. Protein concentrations were measured using the Bradford assay.

\section{Measurements of oxidative DNA damage}

DNA was extracted from mouse embryonic fibroblasts with the DNeasy Tissue Kit (Qiagen Inc., Mississauga, $\mathrm{ON}$ ) according to the manufacturer's protocol. Abasic sites in genomic DNA were quantified with the Oxidative DNA Damage Kit from Kamiya Biomedical Company (Seattle, WA). Briefly, this kit contains an aldehyde reactive reagent (N'-aminooxymethylcarbonylhydrazinoD-biotin), which reacts with the open ring form of apurinic sites in DNA. Oxidative attack by hydroxyl radicals on the deoxyribose moiety will lead to the release of free bases from DNA, generating abasic or apurinic sites. The aldehyde reagent will thus tag apurinic sites with biotin. The number of biotin-tagged apurinic sites was quantified using conjugated avidin-horse radish peroxidase followed by a colorimetric detection of peroxidase.

\section{Measurements of reduced glutathione}

Intracellular levels of glutathione (GSH) were quantified with the ApoGSH Glutathione Detection Kit from Bio Vision (Mountain View, CA). The assay utilizes monochlorobimane (MCB), a dye that appears to form adducts exclusively with GSH. The GSH-bound MCB dye fluoresces blue. Fluorescence was measured with a Fluoroskan Ascent fluorescence spectrophotometer (Thermo Electron Inc., Milford, MA). The excitation and emission wavelengths used were $355 \mathrm{~nm}$ and 460 $\mathrm{nm}$, respectively.

\section{Measurements of ATP and ADP}

Intracellular levels of ATP and ADP were quantified with the ApoSensor ADP/ATP ratio assay kit from Bio Vision (Mountain View, CA). The assay utilizes the enzyme luciferase to catalyze the formation of light from ATP and luciferin. ADP levels are measured by conversion to ATP that is subsequently detected using the same reaction. Luminescence was measured with a Luminoskan Ascent luminometer (Thermo Electron Inc., Milford, MA).

\section{Measurements of inner mitochondrial transmembrane potential}

The inner mitochondrial transmembrane potential of mouse embryonic fibroblasts was determined using tetramethylrhodamine ethyl ester (TMRE). Cells were incubated in a culture medium containing $100 \mu \mathrm{M}$ TMRE for $15 \mathrm{~min}$ in the dark at $37^{\circ} \mathrm{C}$. Fresh medium was then added after washing cells twice with PBS to remove extracellular TMRE. Cells were harvested and fluorescence intensity of TMRE was detected with a Fluoroskan Ascent fluorescence spectrophotometer (Thermo Electron Inc., Milford, MA). The excitation and emission wavelengths used were $544 \mathrm{~nm}$ and $590 \mathrm{~nm}$, respectively.

\section{Statistical analysis}

Data are presented as means \pm SEM. The unpaired Student's $t$-tests were all performed using two-tailed hypothesis and equal variance. Differences between classes were considered significant at $P$-value lower than 0.05 in all statistical analyses. All statistical analyses were performed with $\mathrm{R}$ version 2.6.0 http://www.r-project.org.

\footnotetext{
Additional file 1: Differential expression profile between untreated and $\mathrm{H}_{2} \mathrm{O}_{2}$-treated wild type mouse embryonic fibroblasts. This table is listing the genes altered more than 2 times with a BenjaminiHochberg adjusted p-value lower than 0.1 while comparing the $\mathrm{H}_{2} \mathrm{O}_{2}$ treated versus non-treated wild type mouse embryonic fibroblasts.

Complete results of microarray analyses are found in additional files 1, 2, 4 , and 5.

Click here for file

[http://www.biomedcentral.com/content/supplementary/1471-2164-11127-S1.XLS ]
} 
Additional file 2: Differential expression profile between untreated and $\mathrm{H}_{2} \mathrm{O}_{2}$-treated Wrn helicase mutant mouse embryonic

fibroblasts. This table is listing the genes altered more than 2 times with a Benjamini-Hochberg adjusted $\mathrm{p}$-value lower than 0.1 while comparing the $\mathrm{H}_{2} \mathrm{O}_{2}$ treated versus non-treated Wrn helicase mutant mouse embryonic fibroblasts. Complete results of microarray analyses are found in additional files 1, 2, 4, and 5.

Click here for file

[http://www.biomedcentral.com/content/supplementary/1471-2164-11127-S2.XLS ]

Additional file 3: Genes commonly altered in both $\mathrm{H}_{2} \mathrm{O}_{2}$-treated wild type and Wrn helicase mutant mouse embryonic fibroblasts. This table is listing the common significant genes altered in the same direction in Wrn mutant and wild type mouse embryonic fibroblasts. The primers used for the real time RT-PCR analyses are shown in the additional file 3 .

Click here for file

[http://www.biomedcentral.com/content/supplementary/1471-2164-11127-S3.XLS ]

Additional file 4: Primers used for real time RT-PCR. This table contains the sequence of the oligonucleotides that were used for the real time RT-PCR with the reaction conditions. Complete results of microarray analyses are found in additional files $1,2,4$, and 5 .

Click here for file

[http://www.biomedcentral.com/content/supplementary/1471-2164-11127-S4.XLS ]

Additional file 5: Differential expression profile between wild type and Wrn helicase mutant mouse embryonic fibroblasts. This table is listing the genes altered more than 2 times with a Benjamini-Hochberg adjusted $p$-value lower than 0.1 while comparing the Wrn mutant versus the wild type mouse embryonic fibroblasts. Complete results of microarray analyses are found in additional files 1, 2, 4, and 5 . Click here for file

[http://www.biomedcentral.com/content/supplementary/1471-2164-11127-S5.XLS ]

\section{Acknowledgements}

We are grateful to Dr D. Batchvarov (Centre de Recherche en Cancérologie, Qc, Canada) for microarray hybridization services and for Dr Alan Anderson (Centre de Recherche en Cancérologie, Qc, Canada) for reading the manuscript. This work was supported by a grant from the Canadian Institutes of Health Research to ML. ML is a senior scholar of the Fonds de la recherche en santé du Québec.

\section{Authors' contributions}

All authors contributed to the overall experimental design. AL performed the RNA extraction and the real time RT-PCR experiments. RVNT established the mouse embryonic fibroblasts and performed the TMRE and ROS measurements. EP performed all statistical analyses. CG performed the DNA damage and GSH measurements. ML drafted the manuscript. All authors read, contributed to, and approved the final manuscript.

\section{Competing interests}

The authors declare that they have no competing interests.

Received: 17 November 2009

Accepted: 22 February 2010 Published: 22 February 2010

\section{References}

1. Evans JL, Goldfine ID, Maddux BA, Grodsky GM: Oxidative stress and stress-activated signaling pathways: a unifying hypothesis of type 2 diabetes. Endocrine Reviews 2002, 23:599-622.

2. Furukawa S, Fujita T, Shimabukuro M, Iwaki M, Yamada Y, Nakajima Y, Nakayama O, Makishima M, Matsuda M, Shimomura I: Increased oxidative stress in obesity and its impact on metabolic syndrome. The Journal of Clinical Investigation 2004, 114:1752-1761.
3. Martin J, Kelly DJ, Mifsud SA, Zhang Y, Cox AJ, See F, Krum H, WilkinsonBerka J, Gilbert RE: Tranilast attenuates cardiac matrix deposition in experimental diabetes: role of transforming growth factor-beta. Cardiovascular Research 2005, 65:694-701.

4. Barzilai A, Yamamoto Kl: DNA damage responses to oxidative stress. DNA Repair (Amsterdam) 2004, 3:1109-1115

5. Hasty P, Campisi J, Hoeijmakers J, van Steeg H, Vijg J: Aging and genome maintenance: lessons from the mouse?. Science 2003, 299:1355-1359.

6. von Zglinicki T: Oxidative stress shortens telomeres. Trends in Biochemical Sciences 2002, 27:339-344.

7. Kipling D, Davis T, Ostler EL, Faragher RG: What can progeroid syndromes tell us about human aging?. Science 2004, 305:1426-1431.

8. Sohal RS, Ku HH, Agarwal S, Forster MJ, Lal H: Oxidative damage, mitochondrial oxidant generation and antioxidant defenses during aging and in response to food restriction in the mouse. Mechanisms of Ageing and Development 1994, 74:121-133.

9. Beckman $\mathrm{KB}$, Ames $\mathrm{BN}$ : The free radical theory of aging matures. Physiological Reviews 1998, 78:547-581.

10. Martin GM: mutagenesis and antimutagenesis in aging research. Mutation Research 1996, 350:35-41.

11. Epstein CJ, Martin GM, Schultz AL, Motulsky AG: Werner's syndrome a review of its symptomatology, natural history, pathologic features, genetics and relationship to the natural aging process. Medecine 1966, 45:177-221.

12. Sato K, Goto M, Nishioka K, Arima K, Hori N, Yamashita N, Fujimoto Y, Nanko H, Ohara K, Ohara K: Werner's syndrome associated with malignancies: five case reports with a survey of case histories in Japan. Gerontology 1988, 34:212-218.

13. Yu CE, Oshima J, Fu YH, Wijsman EM, Hisama F, Alisch R, Matthews S, Nakura J, Miki T, Ouais S, Martin GM, Mulligan J, Schellenberg GD: Positional cloning of the Werner's syndrome gene. Science 1996, 2:258-262

14. Shen JC, Gray MD, Oshima J, Kamath-Loeb AS, Fry M, Loeb LA: Werner syndrome protein. I. DNA helicase and dna exonuclease reside on the same polypeptide. The Journal of Biological Chemistry 1998, 273:34139-34144.

15. Kamath-Loeb As, Shen JC, Loeb LA, Fry M: Werner syndrome protein. II. Characterization of the integral $3^{\prime} \rightarrow>5^{\prime}$ DNA exonuclease. The Journal of Biological Chemistry 1998, 273:34145-34150.

16. Ahn B, Harrigan JA, Indig FE, Wilson DM, Bohr VA: Regulation of WRN helicase activity in human base excision repair. Journal of Biological Chemistry 2004, 279:53465-53474.

17. Ghosh A, Rossi ML, Aulds J, Croteau D, Bohr VA: Telomeric D-loops containing 8-oxo-2'-deoxyguanosine are preferred substrates for Werner and Bloom syndrome helicases and are bound by POT1. The Journal of Biological Chemistry 2009, 284:31074-31084.

18. Pagano G, Zatterale A, Degan P, d'Ischia M, Kelly FJ, Pallardó FV, Calzone R, Castello G, Dunster C, Giudice A, Kilinç Y, Lloret A, Manini P, Masella R, Vuttariello $E$, Warnau M: In vivo prooxidant state in Werner syndrome (WS): results from three WS patients and two WS heterozygotes. Free Radical Research 2005, 39:529-533.

19. Oliver CN, Ahn BW, Moerman EJ, Goldstein S, Stadtman ER: Age-related changes in oxidized proteins. Journal of Biological Chemistry 1987, 262:5488-5491.

20. Deschênes F, Massip L, Garand C, Lebel M: In vivo misregulation of genes involved in apoptosis, development and oxidative stress in mice lacking both functional Werner syndrome protein and poly(ADP-ribose) polymerase-1. Human Molecular Genetics 2005, 14:3293-3308.

21. Lebel M, Lavoie J, Gaudreault I, Bronsard M, Drouin R: Genetic cooperation between the Werner syndrome protein and poly(ADP-ribose) polymerase- 1 in preventing chromatid breaks, complex chromosomal rearrangements, and cancer in mice. The American Journal of Pathology 2003, 162:1559-1569.

22. Lavoie J, Carter R, Drouin R, Lebel M: Increased frequency of multiradial chromosome structures in mouse embryonic fibroblasts lacking functional Werner syndrome protein and poly(ADP-ribose) polymerase-1. Cancer Genetics and Cytogenetics 2005, 156:134-143.

23. Massip L, Garand C, Turaga RVN, Deschênes F, Thorin E, Lebel M: Increased insulin, triglycerides, reactive oxygen species, and cardiac fibrosis in mice with a mutation in the helicase domain of the Werner Syndrome gene homologue. Experimental Gerontology 2006, 41:157-168. 
24. Massip L, Garand C, Paquet ER, Cogger VC, O'Reilly JN, Tworek L, Hatherell A, Taylor CG, Thorin E, Zahradka P, Le Couteur DG, Lebel M: Vitamin $C$ restores healthy aging in a mouse model for Werner syndrome. The FASEB Journal 2009, 24:158-172.

25. Ragheb R, Shanab GM, Medhat AM, Seoudi DM, Adeli K, Fantus IG: Free fatty acid-induced muscle insulin resistance and glucose uptake dysfunction: evidence for PKC activation and oxidative stress-activated signaling pathways. Biochemical and Biophysical Research Communications 2009, 389:211-216

26. Fu JH, Sun $H S$, Wang $Y$, Zheng WQ, Shi ZY, Wang QJ: The Effects of a Fatand Sugar-Enriched Diet and Chronic Stress on Nonalcoholic Fatty Liver Disease in Male Wistar Rats. Digestive Diseases and Sciences 2009.

27. de Magalhães JP, Migeot V, Mainfroid V, de Longueville F, Remacle J, Toussaint O: No increase in senescence-associated beta-galactosidase activity in Werner syndrome fibroblasts after exposure to $\mathrm{H} 2 \mathrm{O} 2$. Annals of the New York Academy of Sciences 2004, 1019:375-378.

28. von Kobbe C, May A, Grandori C, Bohr VA: Werner syndrome cells escape hydrogen peroxide-induced cell proliferation arrest. The FASEB Journal 2004, 18:1970-1972.

29. Massip L, Garand C, Labbé A, Perreault E, Turaga RVN, Bohr VA, Lebel M: Depletion of WRN protein causes RACK1 to activate several protein kinase C isoforms. Oncogene 2009.

30. Huang S, Lee L, Hanson NB, Lenaerts C, Hoehn H, Poot M, Rubin CD, Chen DF, Yang CC, Juch $H$, Dorn T, Spiegel R, Oral EA, Abid M, Battisti C, Lucci-Cordisco E, Neri G, Steed EH, Kidd A, Isley W, Showalter D, Vittone JL, Konstantinow A, Ring J, Meyer P, Wenger SL, von Herbay A, Wollina U, Schuelke M, Huizenga CR, Leistritz DF, Martin GM, Mian IS, Oshima J: The Spectrum of WRN Mutations in Werner Syndrome Patients. Human Mutations 2006, 27:558-567.

31. Lebel $M$, Leder $P$ : A deletion within the murine Werner syndrome helicase induces sensitivity to inhibitors of topoisomerase and loss of cellular proliferative capacity. Proceedings of the National Academy of Sciences of the United States of America 1998, 95:13097-13102.

32. Lebel M, Spillare EA, Harris CC, Leder P: Werner syndrome gene product co-purifies with the DNA replication complex and interact with PCNA and topoisomerase I. Journal of Biological Chemistry 1999, 274:37795-37799.

33. Turaga RV, Paquet ER, Sild M, Vignard J, Garand C, Johnson FB, Masson JY, Lebel M: The Werner syndrome protein affects the expression of genes involved in adipogenesis and inflammation in addition to cell cycle and DNA damage responses. Cell cycle 2009, 8:2080-2092.

34. Graier WF, Malli R, Kostner GM: Mitochondrial protein phosphorylation: instigator or target of lipotoxicity?. Trends in Endocrinology and Metabolism 2009, 20:186-193.

35. Kohda Y, Gemba M: Cephaloridine induces translocation of protein kinase $C$ delta into mitochondria and enhances mitochondrial generation of free radicals in the kidney cortex of rats causing renal dysfunction. Journal of Pharmacological Sciences 2005, 98:49-57.

36. Sambrook J, Fritsch EF, Maniatis T: Molecular Cloning: A Laboratory Manual Plainview, New York: Cold Spring Harbor Laboratory Press 1989.

37. Dennis G Jr, Sherman BT, Hosack DA, Yang J, Gao W, Lane HC, Lempicki RA: DAVID: Database for Annotation, Visualization, and Integrated Discovery. Genome Biology 2003, 4:P3.

doi:10.1186/1471-2164-11-127

Cite this article as: Labbé et al.: Expression profiling of mouse embryonic fibroblasts with a deletion in the helicase domain of the Werner Syndrome gene homologue treated with hydrogen peroxide. BMC Genomics 2010 11:127.

\section{Submit your next manuscript to BioMed Central and take full advantage of:}

- Convenient online submission

- Thorough peer review

- No space constraints or color figure charges

- Immediate publication on acceptance

- Inclusion in PubMed, CAS, Scopus and Google Scholar

- Research which is freely available for redistribution 